|| Print ISSN: 2589-7837 || Online ISSN: 2581-3935 ||

International Journal of Medical Science and Diagnosis Research (IJMSDR)

Available Online at www.ijmsdr.com

NLM (National Library of Medicine ID: 101738824)

Original Research Article

Volume 5, Issue 9; September:2021; Page No. 07-12

\title{
Comparative Evaluation of the Effect of Topical Fluoride on the Micro Hardness of Various Restorative Materials- an in Vitro Study
}

\section{Abhraleen Chakraborty ${ }^{1}$, Deepti Jawa Singh ${ }^{2}$, Rani Somani $^{3}$, Shipra Jaidka ${ }^{4}$,} Anu Bhat ${ }^{5}$, Poonam Sharma ${ }^{6}$

${ }^{1}$ MDS, Paedodontics and Preventive Dentistry, Private Practitioner, Denta Cure Dental Clinic, Kolkata, West Bengal, India.

${ }^{2}$ Professor, Department of Pedodontics and Preventive Dentistry, Divya Jyoti College of Dental Science and Research, Modinagar, India.

${ }^{3}$ Professor and Head, Department of Pedodontics and Preventive Dentistry, Divya Jyoti College of

Dental Science and Research, Modinagar, India.

${ }^{4}$ Professor, Department of Pedodontics and Preventive Dentistry, Divya Jyoti College of Dental Science and Research, Modinagar, India.

${ }^{5}$ Assistant Professor, Department of Paedodontics and Preventive Dentistry, B.R.S Dental College and Hospital Panchkula, Haryana, India.

${ }^{6}$ P.G Student, Department of Paedodontics and Preventive Dentistry, B.R.S Dental College and Hospital Panchkula, Haryana, India.

\section{Conflicts of Interest: Nil}

Corresponding author: Abhraleen Chakraborty

DOI: https://doi.org/10.32553/ijmsdr.v5i9.845

\section{Abstract:}

Introduction: Dental caries considered to be a multifactorial disease requires meticulous management and prevention. For prevention the most successful and commonly used agent is fluoride and if applied topically by means of APF gel it has a success rate of around $60 \%$.

Aims and objectives: To evaluate and compare the micro hardness of the restorative materials after the application of APF gel. To evaluate the effect of topical fluoride on the micro hardness of various restorative materials using universal testing machine as well as to compare the micro hardness of the restorative materials after the application of APF gel.

Materials and methods: 80 standardized restorative pellets made with various restorative materials constituted the sample size for the evaluation of micro hardness with and without the application of APF gel on the prepared restorative pellets. The prepared 80 molds were equally distributed for the preparation of 20 restorative pellets of four restorative materials each (viz.) Glass Ionomer Cement, Zirconomer, Amalgomer, Cention-N. Out of 20 samples prepared 10 samples were considered as control, which were tested without the application of APF gel. While 10 samples were taken as experimental, which were conditioned with APF gel before the test.

Results: The result of the microhardness test after the application of fluoride gel showed that the highest microhardess was shown by Group III Amalgomer CR with mean 52.62 \pm 0.65 . The other materials in the order of decreasing hardness were Group IV Cention N 50.52 \pm 0.69 , Group II Zirconomer $46.80 \pm 0.68$ and least for Group I conventional Gic $43.38 \pm 0.53$. The percentage reduction of micro hardness after application of APF gel was recorded highest in GIC type IX followed by Amalgomer CR, Cention $\mathrm{N}$ and 
Zirconomer. Zirconomer has the least percentage reduction of micro hardness after application of APF gel amongst all the restorative materials.

Keywords: APF gel, Amalgomer CR, Cention N, micro hardness, topical fluoride, Zirconomer.

\section{Introduction:}

Dental caries is the most prevalent oral disease in the world population with a prevalence of $49-83 \%$ in the world and $84-85 \%$ in India. ${ }^{1}$ Restoring carious teeth is one of the major treatment needs of young children but it is always beneficial to prevent the carious lesion at its earliest stage and for prevention the most successful and commonly used agent is topical fluoride. Apart from prevention, if caries progresses the lesion should be excavated and restored accordingly. Materials like Glass Ionomer Cements has been extensively used as restorative materials in the primary dentition because of their aesthetics, biocompatibility, ability to release fluoride, rechargeability, and chemical bonding to enamel and dentine. Since its inception in 1960 by Kent and Wilson Glass Ionomer cement has gained success as a restorative, luting as well as lining material in pediatric dentistry. ${ }^{2}$ It has been widely used in dentistry to have long-term durability in the oral cavity and be an excellent barrier against caries. But one of the major drawbacks of conventional GIC is its weak mechanical properties like brittleness, low strength, and toughness. To overcome the drawbacks, the conventional GIC has undergone innumerable changes and inclusions in its properties and composition. Thus in recent times materials with increased strength than GIC but retaining the features like esthetics, anti-cariogenic potential and chemo-mechanical attachment with tooth structure has been into practice.

Amalgomer $\mathrm{CR}$ is another such tooth-coloured material which defines a new class of restorative Glass Ionomer that promises the strength and durability of amalgam with the protective benefits of Glass Ionomer while completely eliminating the hazard of mercury. The material includes the particulate ceramic component with attention of increasing its strength supposedly without sacrificing appearance or other general characteristics of GIC. The inhibitory actions of Amalgomer $\mathrm{CR}$ can be attributed to the coarse nature of its particles contributing to the fluoride release. This tooth-coloured product is proposed by the manufacturer to combine the high strength of a metallic restorative, and the aesthetics and other advantages of glass-ionomers. ${ }^{4}$

Cention $\mathrm{N}$ was introduced in 2017, which is an alkasite restorative material.

Alkasite refers to a new category of GIC restorating material, which like compomer or ormocer, is essentially a subgroup of the composite material class. This new category utilizes alkaline filler, capable of releasing acid-neutralizing ions. The alkaline glass of Cention $\mathrm{N}$ releases hydroxide ions, creating conditions whereby excess acidity due to cariogenic bacterial activity can be neutralized. ${ }^{5}$ It has been reported that the application of APF gel could recharge the fluoride content of exhausted Glass Ionomer Cements (Yip \& Smales, 1999). Thus application of APF gel effectively increases the anti-cariogenic effect of the restorative materials and in turn prevents caries in the adjacent tooth. However, APF gel contains hydrofluoric acid and phosphoric acid (ElBadrawy, McComb \& Wood, 1993) with a $\mathrm{pH}$ of 3.5 phosphoric acid has the ability to etch glass particles (Council on Dental Materials, Instruments, and Equipment, 1988). Hydrofluoric acid is more destructive than phosphoric acid because it can etch glass at lower temperatures too (Kula et al, 1986). Thus due to the high reactivity of fluoride agents used in topical fluoride treatments, there can be some potential adverse effects on various esthetic restorative materials.

Thus in light of the above knowledge it was aimed to evaluate the micro hardness of the various restorative materials after the application of topical fluoride and in turn to ascertain if APF gel can be used as an adjunct in rehabilitation for the children having restorations already.

\section{Materials and Method}

In the study, four different restorative materials were used to prepare 80 standardized restorative material pellets. The selected restorative materials 
were Glass Ionomer Cement type IX, Zirconomer, Amalgomer CR and Cention-N. For making the pellets, autoclavable standardized molds of $4 \mathrm{~mm}$ internal diameter was taken. Each material was mixed according to the manufacturer's instructions. The molds were placed on glass slab. The mixed restorative cement was carried with the plastic filling instrument and placed into the mold and then condensed. The pellets were allowed to set at room temperature for 15 mins. Each mold was then cut with a BP blade longitudinally. Thus the prepared eighty restorative material pellets were obtained from four groups, each having 20 pellets in number namely Group I (Glass Ionomer Cement type IX ), Group II (Zirconomer), Group III (Amalgomer CR), Group IV (Cention-N) and color coded with green, violet, orange and yellow respectively.

Out of 20 samples prepared from each group 10 samples were considered as control, which were tested without the application of APF gel. While 10 samples were taken as experimental, which were conditioned with APF gel before the micro hardness test.

The storage medium for the entire study was distilled water. Thereafter the pellets were incubated to stimulate oral condition in an incubator at $37 \mathrm{o}$ for 24 hours. $1.23 \%$ APF gel was applied on the surface of the restorative pellets of the experimental groups and were kept for $4 \mathrm{mins}$. After topical fluoride treatment, the pellets were thoroughly rinsed with distilled water and were dried with a chip blower. 6 The restorative pellets from all the groups were then subjected to micro hardness testing using Vickers Micro Hardness Testing Machine.

\section{Results:}

The mean micro hardness values before and after the application of APF gel were calculated and were subjected to statistical analysis. The data was then tabulated and were statically analyzed using Paired T test (to compare the mean values from the same material), and Anova test (as the study included three or more categorical, independent group) at a significance level of $(P<0.05)$.. Results showed that there was a non-significant reduction in micro hardness in all the restorative materials after the application of APF gel (Table1).

It was noted that the mean micro hardness before and after the application of APF gel of GIC IX (Group I) was $45.11 \pm 0.40$ and $43.38 \pm 0.53$ respectively, Zirconomer (Group II) was $47.77 \pm$ 0.41 and $46.80 \pm 0.68$ respectively, while that of Amalgomer CR (Group III) was $54.55 \pm 0.45$ and $52.62 \pm 0.65$ respectively followed by Cention $\mathrm{N}$ (Group IV) where it was $52.06 \pm 00.45$ and 50.52 \pm 0.69 respectively (Table $\mathbf{1}$, Graph 1).

The mean percentage reduction of micro hardness after the application of APF gel was found to be least in Zirconomer (Group II) with 2.03\%, followed by Cention N (Group IV) with 2.95\%, Amalgomer CR (Group III) with $3.52 \%$ and maximum in GIC type IX with $3.83 \%$. (Table 2 ).

Table 1: Intra group comparison of mean of micro hardness among different groups

\begin{tabular}{|c|c|c|c|c|c|c|c|}
\hline Mean & $\mathbf{N}$ & Std. Deviation & Std. Error Mean & Mean diff. & T value & P value & Mean \\
\hline \multicolumn{8}{|c|}{ GROUP 1 (GIC IX) } \\
\hline Before & 45.11 & 10 & 0.4040 & 0.1278 & \multirow[t]{2}{*}{.9200} & \multirow[t]{2}{*}{5.220} & \multirow[t]{2}{*}{$0.06^{* *}$} \\
\hline After & 43.38 & 10 & 0.5280 & 0.1670 & & & \\
\hline \multicolumn{8}{|c|}{ GROUP 2 (ZIRCONOMER) } \\
\hline Before & 47.77 & 10 & 0.419 & 0.133 & \multirow[t]{2}{*}{1.4100} & \multirow[t]{2}{*}{7.636} & \multirow[t]{2}{*}{$0.13 * *$} \\
\hline After & 46.80 & 10 & 0.6736 & 0.2130 & & & \\
\hline \multicolumn{8}{|c|}{ GROUP 3 (AMALGOMER CR) } \\
\hline Before & 54.55 & 10 & 0.4528 & 0.1432 & \multirow[t]{2}{*}{2.2500} & \multirow[t]{2}{*}{9.410} & \multirow[t]{2}{*}{$0.059 * *$} \\
\hline After & 52.62 & 10 & 0.6272 & 0.1983 & & & \\
\hline \multicolumn{8}{|c|}{ GROUP 4 (CENTION N) } \\
\hline Before & 52.06 & 10 & 0.4575 & 0.1447 & \multirow[t]{2}{*}{1.840} & \multirow[t]{2}{*}{6.876} & \multirow[t]{2}{*}{$0.055^{* *}$} \\
\hline After & 50.52 & 10 & 0.6893 & 0.2180 & & & \\
\hline
\end{tabular}

** non significant 
Table 2: Mean percentage reduction of micro hardness among different groups after application of APF gel

\begin{tabular}{|c|c|c|c|c|c|c|c|}
\hline \multirow{2}{*}{ Groups } & \multirow{2}{*}{$\begin{array}{l}\text { Mean } \% \\
\text { Reduction }\end{array}$} & \multirow{2}{*}{$\begin{array}{l}\text { Std. } \\
\text { Deviation }\end{array}$} & \multirow{2}{*}{$\begin{array}{l}\text { Std. } \\
\text { Error }\end{array}$} & \multicolumn{2}{|c|}{$\begin{array}{ll}95 \% & \text { Confidence } \\
\text { interval } & \\
\end{array}$} & \multirow{2}{*}{$\mathrm{F}$ value } & \multirow{2}{*}{$\mathrm{P}$ value } \\
\hline & & & & $\begin{array}{l}\text { Lower } \\
\text { Bound }\end{array}$ & $\begin{array}{l}\text { Upper } \\
\text { Bound }\end{array}$ & & \\
\hline GIC IX & $3.83 \%$ & 1.28 & 0.40 & 4.75 & 7.79 & \multirow{4}{*}{3.4969} & \multirow{4}{*}{$0.07^{* *}$} \\
\hline Zirconomer & $2.03 \%$ & 1.22 & 0.38 & 1.15 & 2.91 & & \\
\hline Amalgomer CR & $3.52 \%$ & 1.60 & 0.50 & 4.67 & 6.05 & & \\
\hline Cention N & $2.95 \%$ & 1.21 & 0.38 & 2.07 & 3.82 & & \\
\hline
\end{tabular}

** non significant

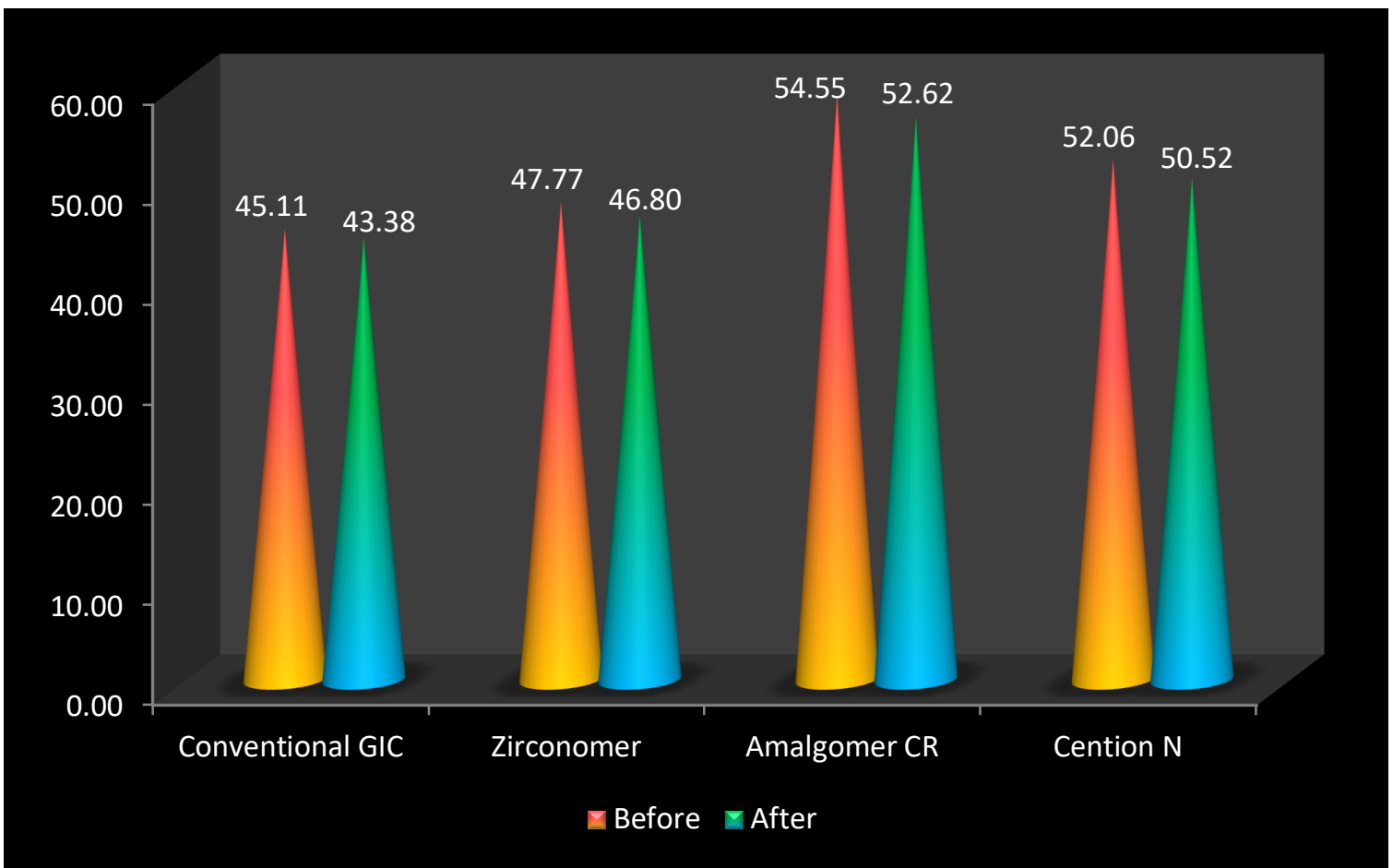

Graph 1: Graphical representation of comparison of mean micro hardness value before and after the application of APF gel in different groups

\section{Discussion}

The effect of the topical application of APF gel on the micro hardness of the restorative materials was evaluated by the Vickers micro hardness testing machine and it was observed that there was a nonsignificant reduction of micro hardness of all the restorative materials after the application of APF gel. Zirconomer showed the least percentage reduction in micro hardness after the application of APF gel. The presence of zirconia fillers and the glass component having better interfacial bonding between matrix and particles subjected to finely controlled micronization was responsible for the enhanced strength. This proved to be crucial for better microhardness than Cention N, Amalgomer CR and GIC type IX. A similar study was done by Sharafeddin F, Azar MR, Feizi N, Salehi R in 2017 on the surface micro hardness of silver and zirconia reinforced glass-ionomers with and without microhydroxyapatite. It was concluded that Zirconia-reinforced glass-ionomer with microhydroxyapatite exhibited significantly 
higher micro hardness in comparison with other groups. $^{7}$

A study was done by Atiyeh Feiz, Narjes Amrollahi, Fereshte Ziayi in 2019 on the comparative evaluation of micro tensile bond strength of four glass-containing materials with primary teeth dentin. They concluded that the micro-tensile bond of Cention $\mathrm{N}$ and RMGI were approximately of equal strength, and Zirconomer showed the highest strength among them. ${ }^{8}$

Cention $\mathrm{N}$ showed lesser percentage reduction in micro hardness after the application of APF gel than GIC type IX and Amalgomer CR but more percentage reduction in micro hardness than Zirconomer. UDMA being the main component of the monomer matrix of Centiion $\mathrm{N}$ which yields moderate viscosity and yields strong mechanical properties which had supposedly made it harder than GIC type IX and Amalgomer CR. Moreover after the application of APF gel the alkaline filler particles increases the hydroxide ions to neutralise the $\mathrm{pH}$ value during acid attacks from the APF gel. The alkaline fillers present in Cention $\mathrm{N}$ has shown to have lesser micro hardness values when

compared with the zirconia fillers in Zirconomer, which proves the reason for Cention $\mathrm{N}$ to show more percentage reduction in micro hardness after the application of APF gel than Zirconomer. A study was done by Paromita Mazumdar, Abiskrita Das and Chiranjan Guha in 2018 on hardness of different restorative materials mainly GIC Type II, Cention N, Nanohybrid Composite Resin and Silver Amalgam. They found that Cention $\mathrm{N}$ had the highest micro hardness values among all the experimental groups. ${ }^{9}$

Amalgomer CR showed lesser percentage reduction in micro hardness than GIC type IX but more percentage reduction in micro hardness after the application of APF gel than Zirconomer and Cention N. The reason might be because the filler content mainly quartz in Glass Ionomer Cement is reinforced by ceramic particles in Amalgomer CR and this ceramic filler was able to react partially with the matrix, which produced considerable bonding and thus increased the overall strength of the restoration while in Glass Ionomer Cement type IX no such reinforcement of filler particles was reported. Amalgomer CR showed more percentage reduction in micro hardness than Cention $\mathrm{N}$ and Zirconomer as Amalgomer CR misses a basic physical property of transformational toughening which is the ability to stop the growth of cracks, and this gives alkaline fillers and the zirconia fillers their unique mechanical properties giving increased hardness to CentionN and Zirconomer. Naveen M Ayad, Salwa A. Elnogoly, Osama M.Badie in 2008 did a similar in-vitro study to check physicomechanical properties of a new esthetic restorative versus dental amalgam and concluded that physico-mechanical properties of Amalgomer CR was significantly superior to dental amalgam. ${ }^{10}$

The percentage reduction in micro hardness after the application of APF gel of Glass Ionomer Cement type IX was found to be highest when compared to Amalgomer $\mathrm{CR}$, Cention $\mathrm{N}$ and Zirconomer as because the matrix formed of polyacrylic hydrogel which has less viscosity and thus are not so stiff to counteract enough stresses or occlusal load might lead to fracture of the restoration because of its lesser strength and decreased solubility when exposed to a acidic environment and thus GIC type IX showed highest percentage reduction in micro hardness after the application of APF gel when compared to all the restorative materials. A study was done by Sara Blanco et al in $\mathbf{2 0 1 7}$ on compressive strength of Glass Ionomers and Composite resins where they stated that GIC type IX had the least compressive strength. ${ }^{11}$

Despite the favourable results, newer materials should be further investigated with a broader sample size and in a clinical trial.

\section{Conclusion}

In the light of the results obtained in the present study, it was observed that there was a non significant decrease in the percentage reduction in micro hardness in all the newer restorative materials used in the study after the application of the APF gel. Thus it is concluded that APF gel can be recommended to be used in patients with 
restorations in their mouth as a preventive measure against future dental caries.

\section{References:}

1. Petersen PE, Bourgeois D, Ogawa H, Estupinan-Day S, Ndiaye C. The global burden of oral diseases and risks to oral health. Bulletin of the World Health Organization. 2005;83:661-9.

2. Crisp S, Wilson AD. Formation of a glassionomer cement based on a lon-leachable glass and polyacrylic acid. Journal of Applied Chemistry and Biotechnology. 1973 Nov;23(11):811-5.

3. Albeshti R, Shahid S. Evaluation of Microleakage in Zirconomer ${ }^{\circledR}$ : A Zirconia Reinforced Glass Ionomer Cement. Acta stomatologica Croatica. 2018 Jun 12;52(2):97104.

4. Mandroli.P Antibacterial effect of Amalgomer $\mathrm{CR}$ and Fuji VII against bacteria causing severe early childhood caries. Journal of Indian Society of Pedodontics and Preventive Dentistry. 2016;34:23-29.

5. S. Deepak, M. S. Nivedhitha. Proximal contact tightness between two different restorative materials - An in vitro study. J Adv Pharm Edu Res 2017;7(2):153-156.

6. Gill NC, Pathak A. Comparative evaluation of the effect of topical fluorides on the micro hardness of various restorative materials: an in vitro study. Journal of Indian Society of
Pedodontics and Preventive Dentistry. 2010 Jul 1;28(3):193.

7. Sharafeddin F, Azar MR, Feizi N, Salehi R. Evaluation of Surface Microhardness of Silver and Zirconia Reinforced Glass-ionomers with and without Microhydroxyapatite. Journal of Dental Biomaterials. 2017 Dec 24;4(4):45460.

8. Feiz A, Amrollahi N, Ziayi F. Comparative Evaluation of Microtensile Bond Strength of Four Glass-Containing Materials with Primary Teeth Dentin. Iranian Journal of Pediatrics. 2019 Aug 1;29(4).

9. Mazumdar P, Das A and Guha C. Comparative evaluation of hardness of different restorative materials (restorative gic, cention n, nanohybrid composite resin and silver amalgam). International Journal Of Advanced research (IJAR). 2018 Nov 29:2017- 399.

10. Neveen M Ayad, Salwa A Elnogoly, Osama M Badie. An In-Vitro Study of the PhysicoMechanical Properties Of a New Esthetic Restorative versus Dental Amalgam. Rev. Clín. Pesq. Odontol. Curitiba. 2008; 4(3):137144.

11. Blanco Lerech S, Frías Tarón S, Taron Dunoyer A, Bustillo Arrieta JM, Díaz Caballero A. Compressive strength of glass ionomer and composite resin. In vitro study. Revista Odontológica Mexicana. 2017 Apr 15;21(2):109-13. 